\title{
New MRI Advances in Post-Operative Assessment of Pelvic Tumors
}

\author{
HEBA AZZAM, M.D. \\ The Department of Diagnostic and Interventional Radiology, Faculty of Medicine, Cairo University
}

\begin{abstract}
Background: Differentiating residual or recurrent tumor from treatment related tissue changes after surgical resection of malignancy is often challenging due to non-specific signal findings by standard MRI with histologic examination remaining the standard reference yet it can't be done in all cases. The addition of contrast-enhanced MRI has proven to be beneficial in addition DWI detects the biologic characteristics of tissue and gives unique data regarding the cellularity and the status of molecular content of water.
\end{abstract}

Aim of Study: In this study we aimed to assess the role of Diffusion-Weighted Imaging (DWI) and contrast-enhanced MR imaging in combination with standard MRI in the evaluation of recurrent intrapelvic malignancy.

Patients and Methods: Prospective study of 108 postoperative patients that require follow-up MRI imaging after resection of intra-pelvic malignancies in isolation or with radiation and/or chemotherapy with mean age of 55 years. Two radiologists prospectively assessed the morphological and qualitative descriptors of the included lesions (restricted diffusion) and quantitative analysis of the ADC maps. The mean ADC value of the lesions was calculated and correlated with the histopathology which was established by means of an open or a core needle biopsy (considered as the standard reference).

Results: There was significant difference between the mean ADC value of recurrent/residual lesions and of benign post-operative changes ( $p$ 0.0001) with high sensitivity of mean ADC (93.1\%) and specificity (85.7\%) ( $p$ value 0.000095$)$.

Conclusion: DWI is a contrast-free modality that allows for both morphological and quantitative analysis. ADC value may not be the proper modality to determine the prognosis of intra pelvic cancer due to overlap values, yet it could aid discrimination of recurrent/residual tumor from post-operative changes as well as being a good predictor of cancer cells that would respond to chemotherapy.

Key Words: Diffusion - ADC value - Magnetic resonance imaging - Recurrent intra pelvic tumors - Postoperative - Post-therapeutic changes.

Correspondence to: Dr. Heba Azzam, E-Mail: heba.m.azzam@gmail.com

\section{Introduction}

EARLY detection of malignant recurrence, before symptoms develop is crucial as survival decreases once patients become symptomatic [1]

The main role of MRI is to assess surgical site for recurrent tumors. MRI is the modality of choice for the distinction between residual or recurrent tumor and post-operative fibrosis or inflammation $\&$ characterization of soft tissue lesions, particularly in defining their composition, extent, compartmental involvement, and relationship to the adjacent neurovasculature [2].

However differentiating residual or recurrent tumor from treatment related tissue changes after surgical resection of malignancy is a common problem due to non-specific signal abnormalities by standard MRI seen as low signal on T1 images and high signal on T2 images [3].

Histologic examination remains the definite means to establish the diagnosis of malignancy, but routine biopsy of all lesions is not practical or cost effective [4].

Contrast-enhanced MRI has been considered as the most precise imaging procedure for detection of tumor recurrence and distinguishing it from post-surgical and post-therapy changes, nevertheless it gives no definitive information about tumor cellularity, therefore, there has been a growing interest in the use of diffusion-weighted imaging for its potential to advance the diagnosis [5].

\footnotetext{
List of Abbreviations:

ADC : Apparent Diffusion Coefficient.

DCE : Dynamic Contrast Enhanced.

DWI : Diffusion Weighted Images.

MRDA : Maximum Restricted Area.

MRI : Magnetic Resonance Imaging.

ROI : Region of Interest.
} 
Diffusion weighted MRI detects the biologic characteristics of tissue and gives unique data regarding the cellularity and the status of molecular content of water. Moreover it has a privilege of short exam duration with no need to use contrast medium [6]

The ADC is a q value that can be quantified measuring signal attenuation being influenced by microscopic motion, including molecular diffusion of water as well as blood microcirculation [7] .

In the current study we evaluated the added value of combining conventional MRI, contrast enhanced MRI and DWI in the evaluation of recurrent intrapelvic malignancy and differentiating it from post-operative changes.

\section{Patients and Methods}

This study is a prospective analysis, approved by the Ethics Committee at Kasr El-Aini Hospital, the cases were referred from the Oncology Clinic in Kasr El-Aini Hospital during the period from September 2016 to August 2018. Tissue pathology was established by mean of an open or a core needle biopsy (considered as the standard reference).

\section{Patients:}

It included 108 patients who were subjected to MRI scanning including pre-contrast, dynamic post contrast as well as diffusion weighted sequences.

\section{Inclusion criteria:}

Post-operative patients that require follow-up MRI imaging after resection of intra-pelvic malignancies in isolation or with radiation and/or chemotherapy.

\section{Exclusion criteria:}

- Cases that lacked pathological confirmation.

- Solid masses less than $1 \mathrm{~cm}$ or complex masses that presented with small solid component (the ADC value could not be evaluated).

\section{Methods:}

MR imaging: MRI was performed for the pelvis using 1.5 Tesla magnet scanner (Achieva Philips medical system). All patients were examined in the supine position using pelvic phased-array coil. Total study time ranged from 30 to 45 minutes. No sedation was used.

\section{MRI imaging protocol:}

A- Cases were examined first by pre-contrast sequences: T1 and T2 WI with fat-suppressed images were acquired in three planes; axial, coronal and sagittal.

B- Diffusion-weighted images: They were performed before the Dynamic Contrast Enhanced (DCE-MRI) acquisition using a "Echo-Planar Imaging" (EPI) sequence with b-values $(0,850$, $1000,1500 \mathrm{~s} / \mathrm{mm}^{2}$ ); and the diffusion image was supplied from "Spectral Adiabatic Inversion Recovery” (SPAIR) MR sequence. Respiratory triggering was used for better resolution.

C-Dynamic contrast-enhanced series: A bolus of contrast (Magnevist (gadopentetatedimeglumine) $0.1 \mathrm{mmol} / \mathrm{kg}$ ) was injected manually intravenous.

\section{Post processing and image analysis:}

Post processing image subtraction was obtained using the software subtraction function available on the work station.

Qualitative and quantitative analysis of the examined masses were done as follows:

I- Qualitative analysis:

1- The morphological features of each lesion were recorded including size, shape, margin, signal characteristics and pattern of enhancement. Fig. $(1 \mathrm{~A}, \mathrm{~B})$.

2- Restricted diffusion was determined by visualization of abnormal bright signal intensity that became enhanced with increasing b values (850 $\rightarrow 1000 \rightarrow 1500)$ at "Diffusion Weighted" (DW) images Fig. (1B,C).

\section{II- Quantitative analysis:}

The ADC values were measured manually by applying ROI at areas of interest avoiding cystic/ necrotic areas Fig. (1C).

\section{Statistical analysis:}

Data were coded and entered using the statistical package SPSS (Statistical Package for the Social Sciences) version 22. Data was summarized using mean, standard deviation, median, minimum and maximum in quantitative data and using frequency (count) and relative frequency (percentage) for categorical data. Comparisons between quantitative variables were done using the Chi square $\left(\mathrm{X}^{2}\right)$ tests [8]. ROC curve was constructed with area under curve analysis performed to detect best cutoff value of ADC for detection of high grade tumors.

$p$-values less than 0.05 were considered as statistically significant. 

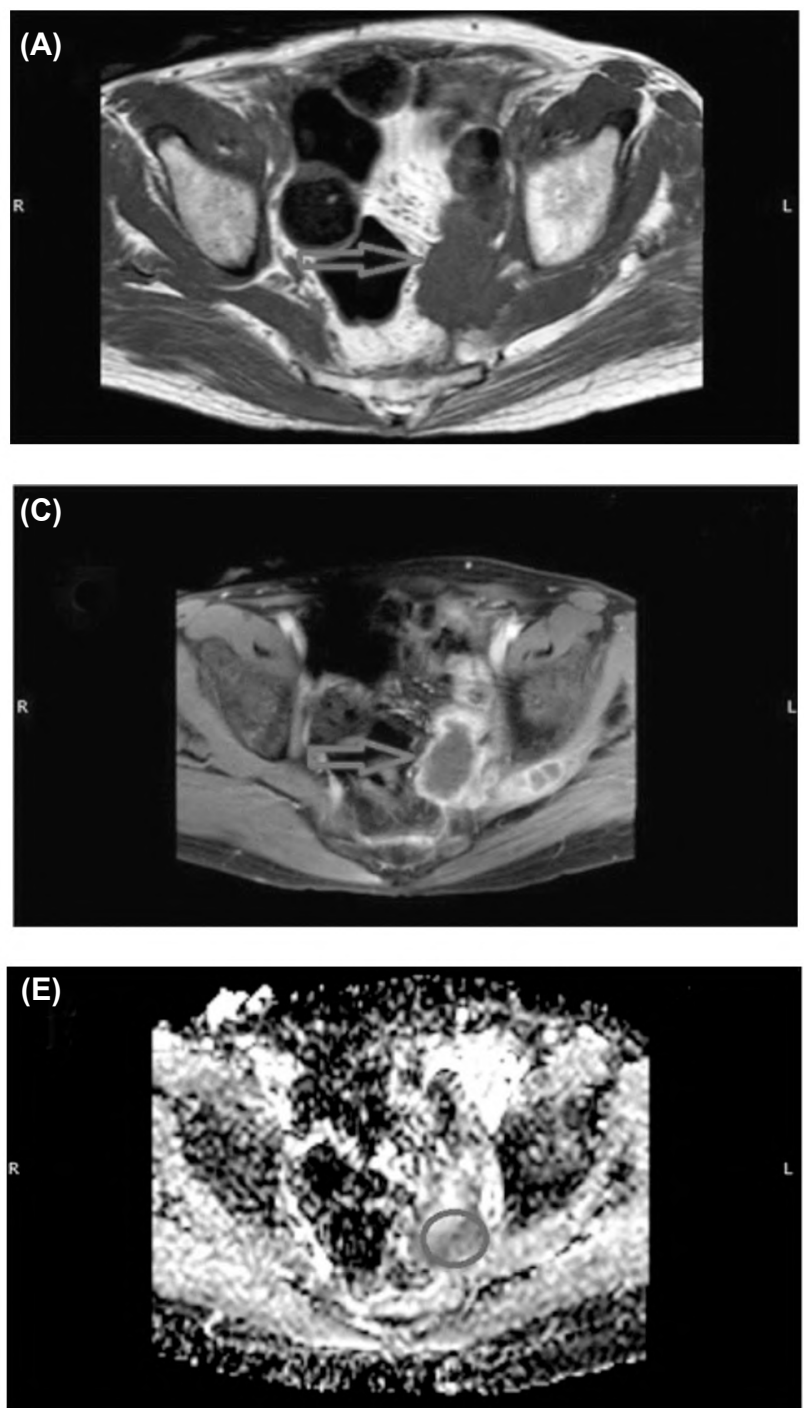
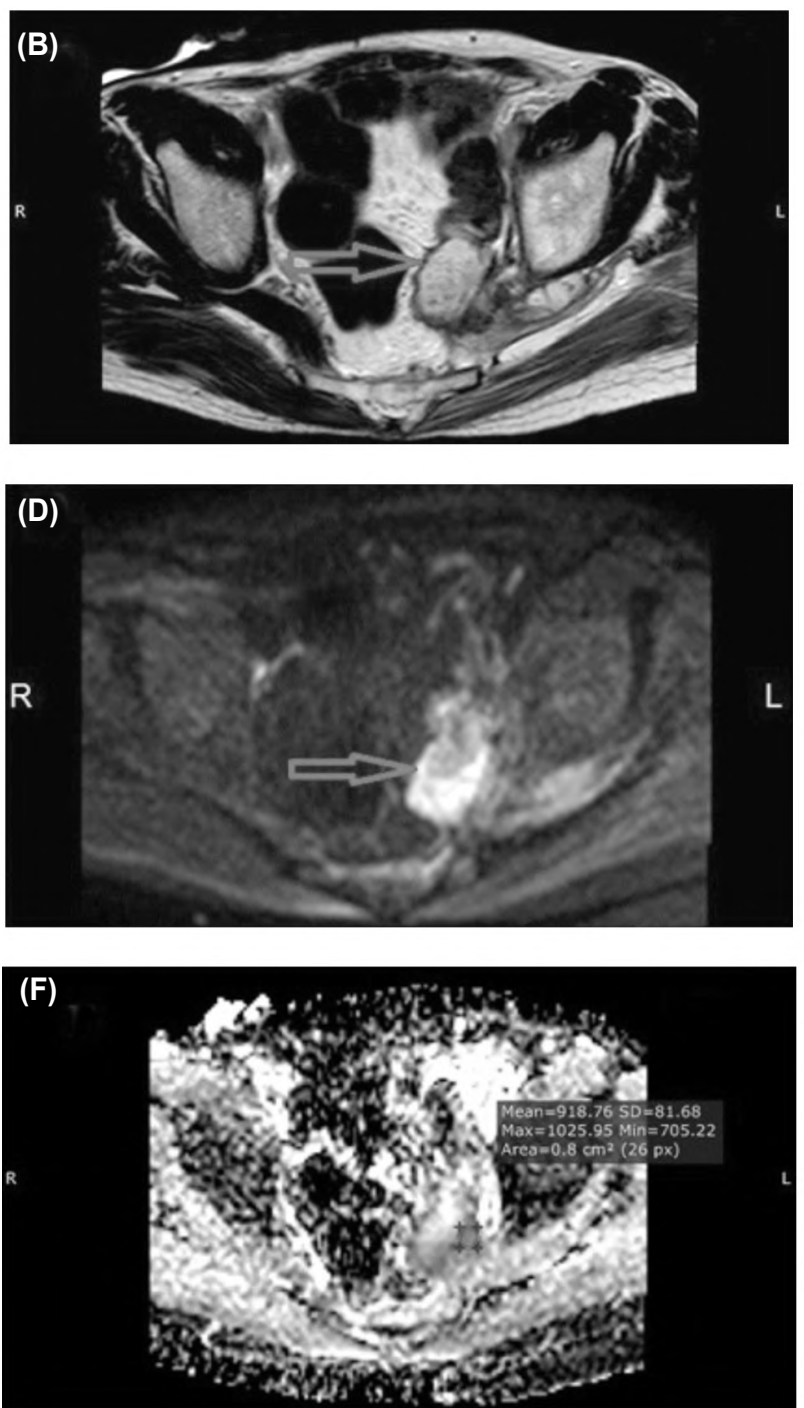

Fig. (1): A 59 year-old, male patient, underwent radical cystectomy for a bladder cancer, post-resection pathology revealed transitional cell carcinoma of urinary bladder, MRI images: (A \& B ) T 1 \&T2 (C \& D) Contrast enhanced image \& DWI at b 800 and $(\mathrm{E} \& \mathrm{~F}) \mathrm{ADC}$ map \& ADC value: 0.9 X $10 \mathrm{~mm} / \mathrm{s}$. A suspicious ill-defined lesion in left pelvis, eliciting low signal in T1 and high signal in T2 showing marginal irregular contrast uptake the lesion corresponded to a high signal intensity in the DWI ( $b=800)$ image, a visibly low signal at the ADC map and recorded low ADC measurements (mean 0.9 X $10 \mathrm{~mm} / \mathrm{s}$ minimum $0.7 \times 10^{-3} \mathrm{~mm} / \mathrm{s}$ ) denoting restricted diffusion pattern.

\section{Results}

108 patients ( 87 females and 21 males) were included in this study, their age ranged from 30 to 72 years (mean age 55), the interval between their operative procedure and the MRI observations analyzed in our study was variable ranging from 5 month up to 5 years post-surgery, with average of about 31 months duration of follow-up.

There were 87 (80\%) cases histologically proven recurrences and residuals having the following histologic diagnoses: Bladder cancer $(n=9)$, cervical cancer $(n=27)$, rectal cancer $(n=12)$, uterine liomy- osarcoma $(n=15)$, endometrial cancer $(n=21)$, ovarian cancer $(n=3)$, and $21(20 \%)$ cases with postoperative inflammation/fibrosis.

In this study, there was significant difference between the mean ADC value of recurrent/residual lesions and of benign post-operative changes ( $p$ $0.0001)$. The mean $\mathrm{ADC}+\mathrm{SD}$ of recurrent/residual lesions was $\left(0.8+0.2 \times 10^{-3}\right) \mathrm{mm}^{2} / \mathrm{sec}$ and of benign post-operative changes $\left(1.8+2.0 \times 10^{-3}\right)$ $\mathrm{mm}^{2} / \mathrm{sec}$. The cut off average ADC value for detecting reçurrent/residual lesions were found to be $\left.<1 \times 10^{-3}\right) \mathrm{mm}^{2} / \mathrm{sec}$ with $85.7 \%$ specificity and $93.1 \%$ sensitivity. 
The Maximum Restricted Area (MRDA) values (Average of $0.5 \times 10^{-3}$ ) $\mathrm{mm}^{2} / \mathrm{sec}$ ) for recurrent/ residual cases compared to (Average of $1.5 \times 10^{-3}$ ) $\mathrm{mm}^{2} / \mathrm{sec}$ ) for benign post-operative changes.

Static post contrast T1-weighted MR imaging achieved $86.2 \%$ sensitivity and specificity of only $43 \%$ in the detection of recurrent/residual disease because mass like enhancement was observed in many cases without recurrence.

The low signal intensity mass at ADC mapping further increased specificity to $71.4 \%$ in the detection of recurrence/residual, $100 \%$ sensitivity.
The study showed high sensitivity of mean $\operatorname{ADC}(93.1 \%)$ and specificity $(85.7 \%)$.

( $p$-value 0.000095 ) (extremely statistically significant) compared to the minimum

ADC sensitivity measurements $(86.2 \%)$ ( $p$ value 0.000668 ). Thus, average ADC should be accompanied with measuring peripheral maximum restricted areas as well. The observed imaging features of recurrent tumors, and post-operative inflammation and fibrosis in the surgical bed as well as the diagnostic performance of each imaging feature in the detection of recurrent/residual disease are summarized in (Tables 1,2) respectively.

Table (1): Imaging features of abnormalities in the surgical bed.

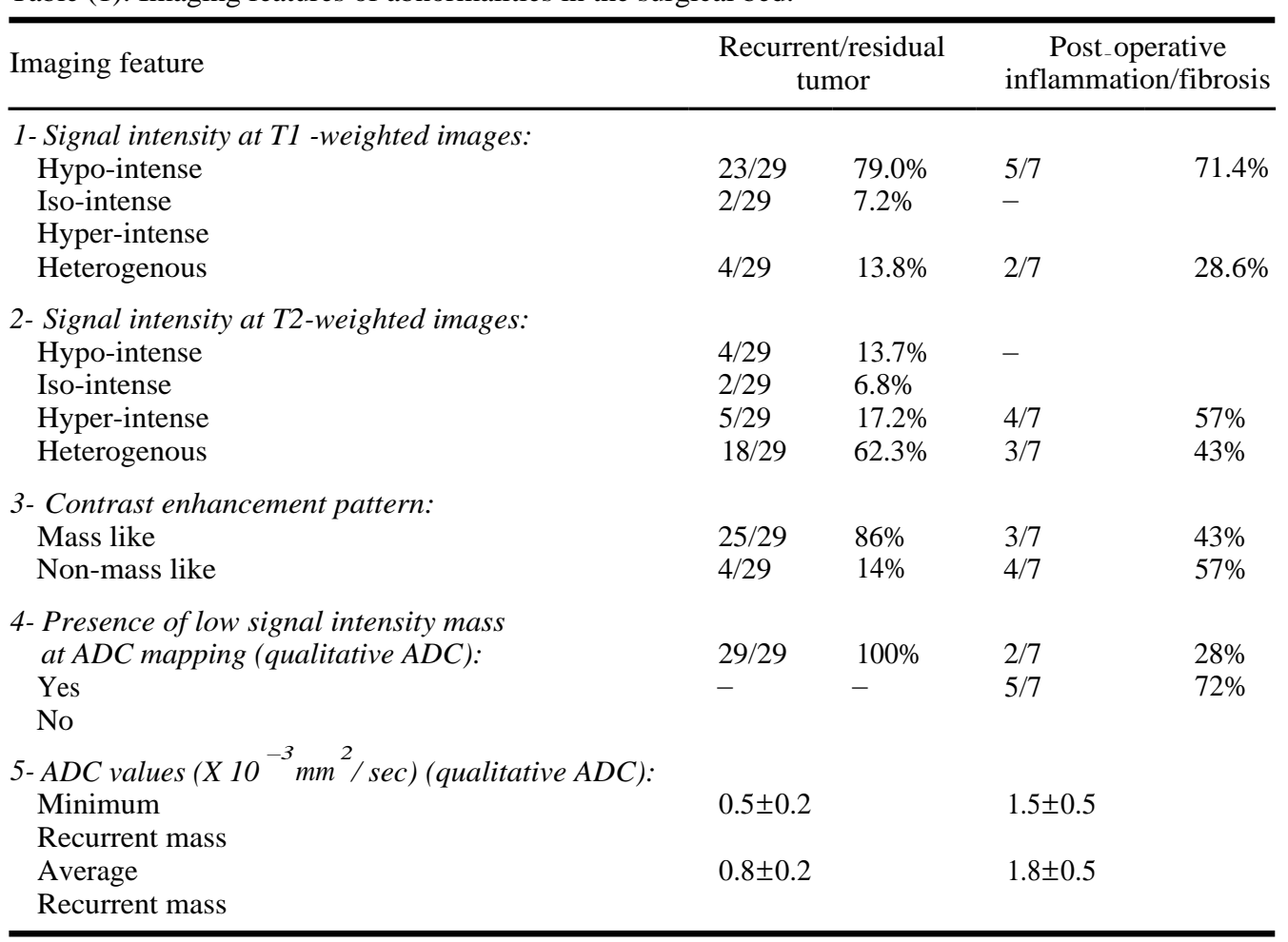

Table (2): Describes the diagnostic performance of each imaging feature in the detection of recurrent/residual disease.

\begin{tabular}{lllll}
\hline Parameter & Sensitivity & Specificity & Accuracy & $p$-value (Fisher's exact test) \\
\hline Hypo-or isointensity at T1-weighted imaging & $86.2 \%$ & $28.2 \%$ & $75 \%$ & 0.57 (insignificant) \\
Hyperintensity at T2-weighted imaging & $79.3 \%$ & $0 \%$ & $63.88 \%$ & 0.317 (insignificant) \\
Mass at T1-weighted post-contrast imaging & $86.2 \%$ & $43 \%$ & $77.7 \%$ & 0.030102 (not quite statistically significant) \\
Low-signal-intensity mass at ADC mapping. & $100 \%$ & $71.4 \%$ & $94.45 \%$ & 0.000056 (extremely statistically significant) \\
Minimum ADC $\leq 0.7$ & $86.2 \%$ & $85.7 \%$ & $86.1 \%$ & 0.000668 (extremely statistically significant) \\
Average ADC $\leq 1$ & $93.1 \%$ & $85.7 \%$ & $91.6 \%$ & 0.000095 (extremely statistically significant) \\
\hline
\end{tabular}

\section{Discussion}

Precise assessment of the operative bed and differentiation of post-operative inflammation/ fibrosis from recurrent tumor is of extreme importance in the diagnosis and treatment planning yet it is often challenging.
Although MRI is an ideal non-invasive technique and superior to other imaging modalities in the evaluation of pelvic abnormalities and the anatomical relation of the visceral organs, conventional MR sequences with T1-and T2-weighted imaging have limited value in the detection of recurrent/residual tumors as the surgical bed is 
often associated with heterogeneous signal intensity and scar tissue that can potentially obscure a recurrence [9].

Some authors reported that the absence of abnormal T2-weighted signal intensity in the surgical bed can't totally exclude recurrence as in minority of cases recurrence can be of low signal intensity on T2-weighted images, yet low signal intensity on T2 weighted images can excluded tumor recurrence with $96 \%$ sensitivity [10]. T1-weighted sequences are also useful for showing architectural distortion associated with a recurrent tumor, which is not well seen on fluid-sensitive images. Hence according to [11] Fayad et al., 2012 when a recurrent tumor is present, it can be fairly obvious on nonenhanced images.
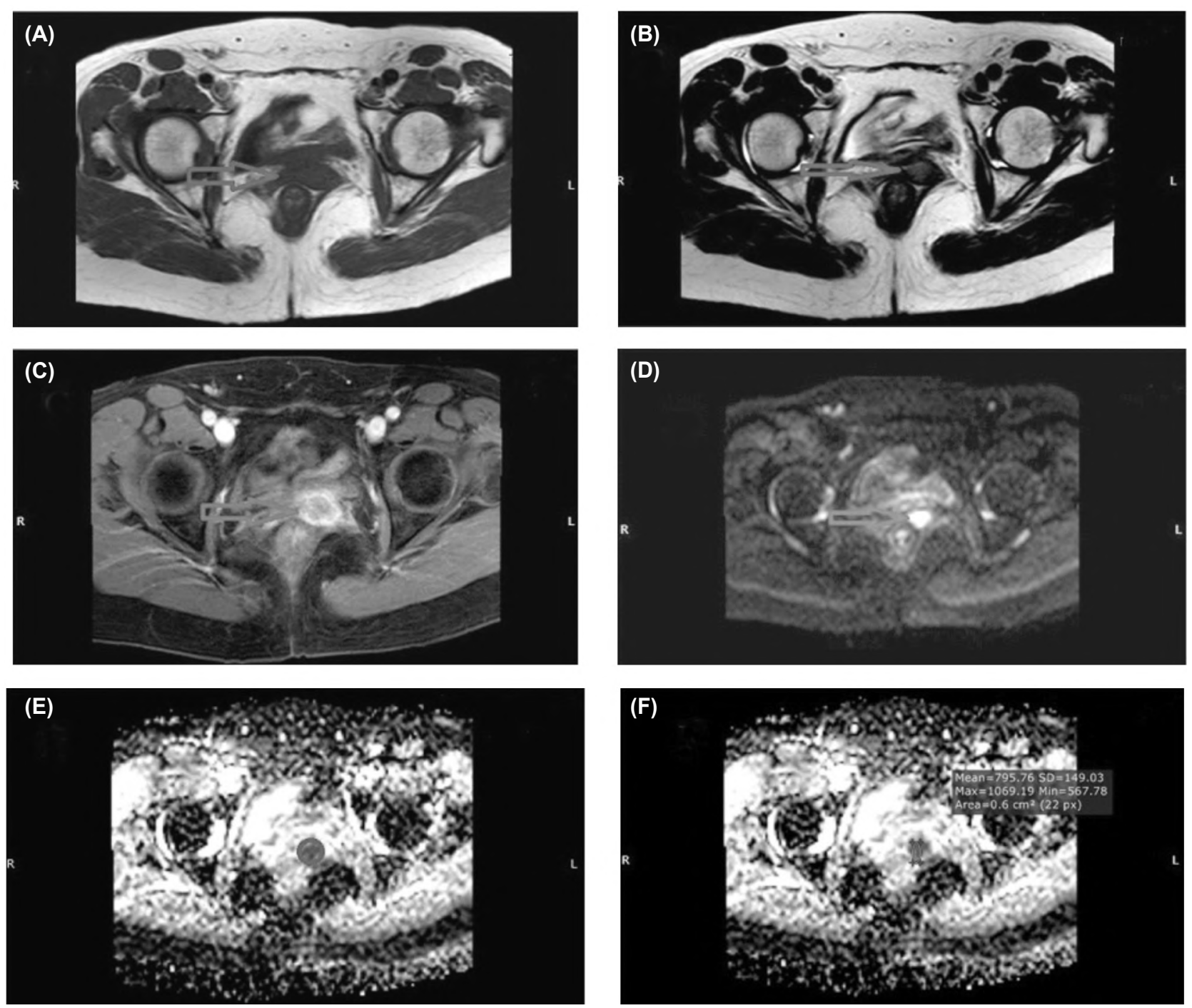

Fig. (2): A 52 year-old, female patient, underwent pan hysterectomy for cervical carcinoma, post-resection pathology revealed recurrent squamous cell carcinoma. MRI imąges: (A \& B) T1 \& T2 (C \& D) Contrast enhanced image \& DWI at b 800 and (E \& F) ADC map \& ADC value: 0.7 X $10 \mathrm{~mm} / \mathrm{s}$. A suspicious ill-defined mass lesion is seen related to the left aspect of vault of vagina, eliciting low signal in $\mathrm{T} 1$ and heterogeneous intermediate signal in $\mathrm{T} 2$ with marginal contrast uptake. The lesion corresponded to a high signal intensity in the DWI image, a visibly low signal at the ADC map and recorded low ADC measurements (mean $0.7 \times 10 \mathrm{~mm} / \mathrm{s}$, minimum $0.5 \times 10^{-3} \mathrm{~mm} / \mathrm{s}$ ) denoting restricted diffusion pattern. 
In this study the sensitivity of the static post contrast T1-weighted sequence in the detection of recurrent/residual tumor with the identification of a mass-like area of enhancement is relatively high ( $86 \%, 75$ of 87 patients). Yet a mass like region of enhancement was observed in 9/21 (43\%) patients without recurrence, resulting in only $43 \%$ specificity for the detection of recurrence. Such a high false-positive rate may lead to unnecessary biopsy of a mass like region of postoperative scar tissue.

The rapid growth of cancer is coupled with change of both anabolism and catabolism affecting its growth and changing the intracellular and extracellular environment. Functional MR imaging techniques-such as Diffusion-Weighted Imaging
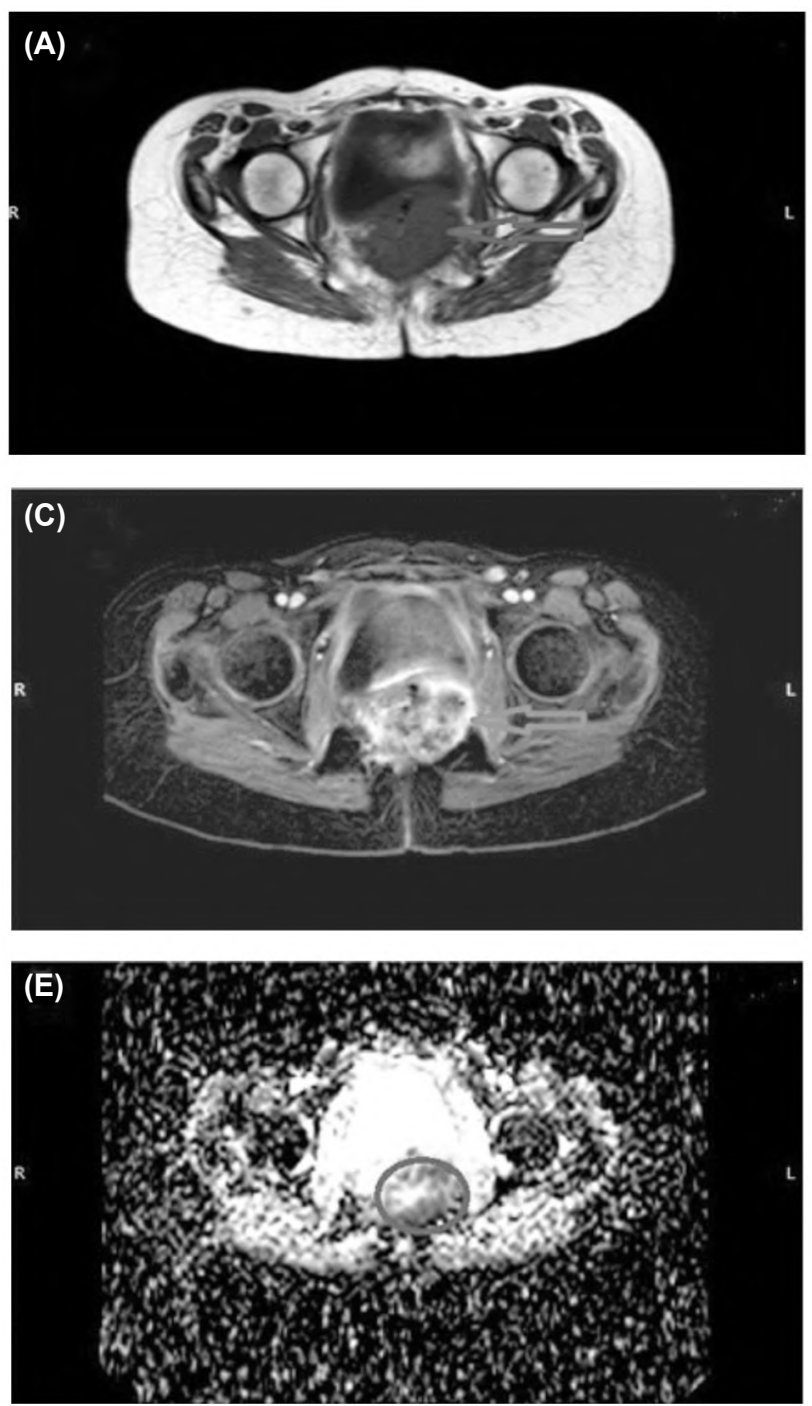

(DWI) and the measured Apparent Diffusion Coefficient (ADC)-are helpful to detect such changes coupled with tumor proliferation [13]. Figs. $(2,3)$.

In this study the detection of low signal intensity lesion at $\mathrm{ADC}$ mapping further increased specificity to $71.4 \%$ in the detection of recurrence/residual lesions. We found that the mean ADC value of the recurrent intrapelvic malignant tumors $0.8 \pm 0.20$ X $10^{-3} \mathrm{~mm}^{2} / \mathrm{s}$ which were significantly different from those of post-operative changes $1.8 \pm 0.20 \mathrm{X}$ $10^{-3} \mathrm{~mm} / \mathrm{s}$ with $p$-value 0.000095 . The addition of qualitative and quantitative assessment of the ADC maps provided $93.1 \%$ sensitivity and specificity $85.7 \%$ in recurrence detection.
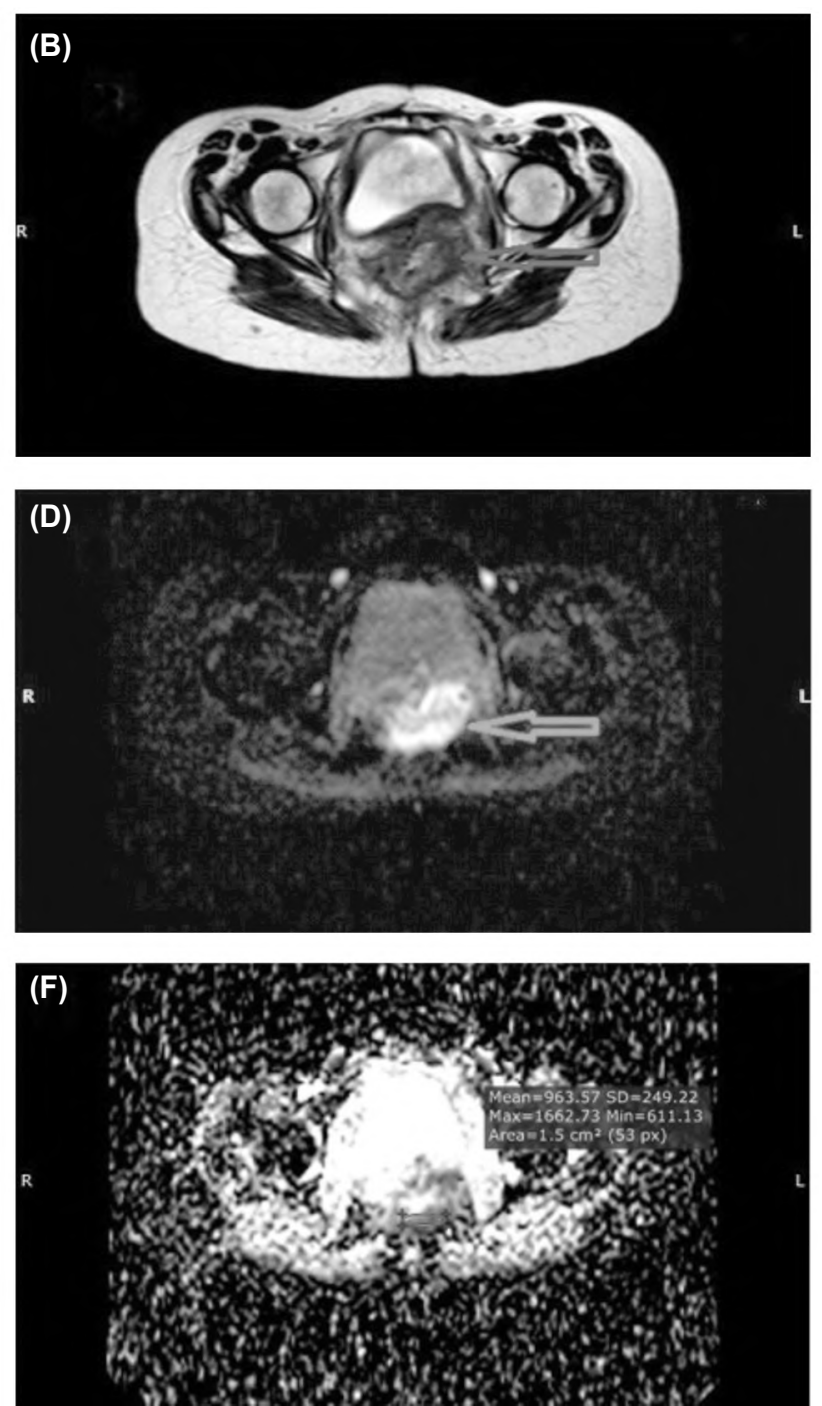

Fig. (3): A 35 year-old, female patient, underwent surgical excision of a rectal cancer, post-resection pathology revealed Adenocarcinoma grade II. MRI images: (A \& B) T1 \& T2 (C \& D) Contrast enhanced image \& DWI at b 800 and (E \& F) ADC map \& ADC value: $0.9 \times 10^{-3} \mathrm{~mm} / \mathrm{s}$. A suspicious surgical bed soft tissue lesion more prominent in the left anterior aspect, is seen inseparable from posterior wall of urinary bladder, eliciting hypointense signal in $\mathrm{T} 1$ weighted images and heterogeneous intermediate signal in T2 weight images with heterogeneous post contrast enhancement. The lesion corresponded to a high signal intensity in the DWI image, a visibly low signal at the ADC, map and recorded low ADC measurements in most restricted part in lesion (mean $0.9 \times 10^{-3} \mathrm{~mm} / \mathrm{s}$, minimum $0.6 \times 10^{-3} \mathrm{~mm} / \mathrm{s}$ ) denoting restricted diffusion pattern (circle). 
This agrees with Nishie et al., [14] who reported that high signal intensity on high-b-value DWIs that demonstrate low signal intensity on apparent diffusion coefficient maps were an indicator of local recurrence of pelvic malignancies, with sensitivity $94 \%$, specificity $72 \%$ of combined T2WI and DWI.

Yet this disagrees with Einarsdóttir et al., [15] who stated that the role of quantitative ADC mapping in the differentiation of benign from malignant soft-tissue lesions has been debated.

Yet, we have to admit that our study was limited by the different pathologies of pelvic malignancies that made it difficult to know if our results can apply to all intra pelvic malignant or not.

\section{Conclusion:}

The addition of contrast enhanced and DW imaging for assessment of recurrent pelvic malignancies have significant added value in differentiating it from post-operative signal abnormalities.

\section{References}

1- KITAJIMA K., YAMASAKI E., KAJI Y., MURAKAMI K. and SUGIMURA K.: Comparison of DWI and PET/CT in evaluation of lymph node metastasis in uterine cancer. World J. Radiol., 28: 4 (5): 207-14, 2012.

2- Del GRANDE F., SUBHAWONG T., WEBER K., et al.: Detection of soft-tissue sarcoma recurrence: Added value of functional MR imaging techniques at 3.0 T. Radiology, 271 (2): 499-511, 2014.

3- KHOO M.M.Y., TYLER P.A. and SAIFUDDIN A.: Diffusion-Weighted Imaging (DWI) in musculoskeletal MRI: A critical review. Skeletal Radiol., 40: 665-81, 2011.

4- CHHABRA A. and SOLDATOS T.: Soft-tissue lesions: When can we exclude sarcoma? American Journal of Roentgenology, 199 (6): 1345-57, 2012.

5- KIDO A., FUJIMOTO K., OKADA T. and TOGASHI K. Advanced MRI in malignant neoplasms of the uterus. J. Magn. Reson. Imaging, 37: 249-64, 2013.
6- BALTZER P.A., BENNDORF M., DIETZEL M., GAJDA M., CAMARA O. and KAISER W.A.: Sensitivity and specificity of unenhanced MR mammography (DWI combined with T2-weighted TSE imaging, ueMRM) for the differentiation of mass lesions. Eur. Radiol., 20 (5): 1101$10,2010$.

7- COSTANTINI M., BELLI P., RINALDI P., BUFI E., GIARDINA G., FRANCESCHINI G., et al.: Diffusionweighted imaging in breast cancer: Relationship between apparent diffusion coefficient and tumour aggressiveness. Clin. Radiol., 65 (12): 1005-12, 2010.

8- CHAN Y.H. Biostatistics102: Quantitative Data-Parametric \& amp; Non-parametric Tests. Singapore Med. J., 44 (8): 391-6, 2003.

9- GARNER H.G., KRANSDORF M.J., BANCROFT L.W. PETERSON J.J. and BERQUIST T.H.: Benign and malignant soft-tissue tumors-post-treatment MR imaging. Radiographics, 29 (119), 34, 2009.

10- VANEL D.: Imaging soft tissue sarcomas: Or from the certainly disastrous present practice, to the possibly shining future. European Journal of Radiology, 69 (2): 199-200, 2009.

11- FAYAD L.M., JACOBS M.A., WANG X., CARRINO J.A. and BLUEMKE D.A.: Musculoskeletal tumors: How to use anatomic, functional, and metabolic MR techniques. Radiology, 265 (2): 340-56, 2012.

12- DIANA A.P., KOSINSKI A.S. and SPRITZER C.E.: Following unenhanced MRI assessment for local recurrence after surgical resection of mesenchymal soft tissue tumors, do additional gadolinium-enhanced images change reader confidence or diagnosis? European Journal of Radiology, 82 (5): 806-13, 2013.

13- SHARMA U., SAH R.G., AGARWAL K., PARSHAD R., SEENU V., MATHUR S.R., et al.: "Potential of Diffusion-Weighted imaging in the characterization of Malignant, Benign, and healthy Breast Tissues and Molecular subtypes of Breast cancer." Frontiers in oncology, 6, 2016.

14- NISHIE A., STOLPEN A.H., OBUCHI M., et al.: Evaluation of locally recurrent pelvic malignancy: Performance of T2-and diffusion-weighted MRI with image fusion. J. Magn. Reson. Imaging, 28: 705-13, 2008.

15- EINARSDÓTTIR H., KARLSSON M., WEJDE J. and BAUER H.C.F.: Diffusion-weighted MRI of soft tissue tumors. European Radiology, 14 (6): 959-63, 2004. 


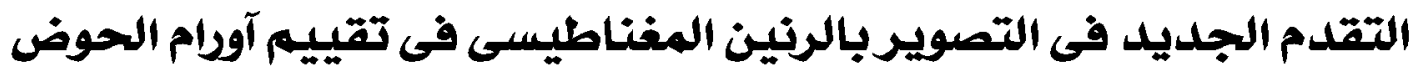 في مرحلة ما بعد الجراحة}

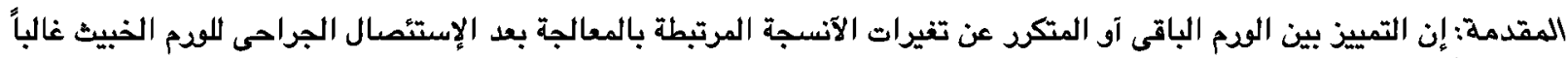

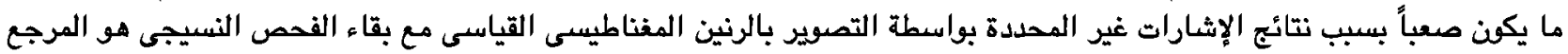

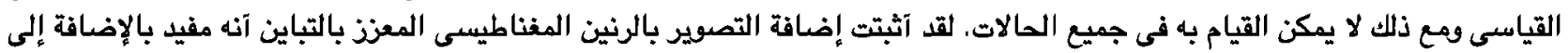
آن DWI يكتشف الذصائص الييولوجية للآتسجة ويعطى بيانات فريدة بشآن الخلوية وحالة المحتوى الجزيئى اللمياه.

الهدف من الدراسة: نى هذه الدراسة، كنا نهذف إلى تقييم دود التصوير المونون الموزع (DWI) والتصوير بالرنين المفناطيسى المحسن

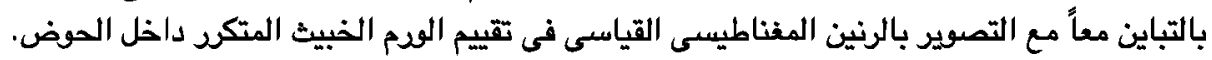

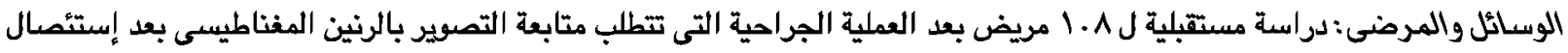

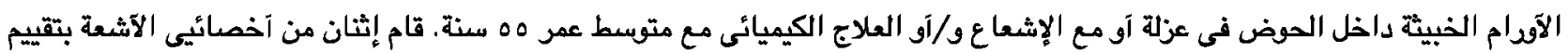

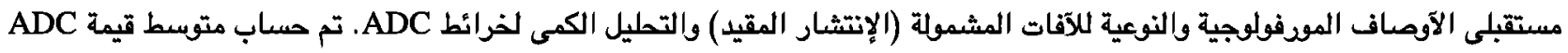
للآثات ومترابطة مع التشريح المرضى الذى تم إنشائه عن طريق خزعة إبرة مفتوحة آو آساسية (تعتبر المرجعية القياسية).

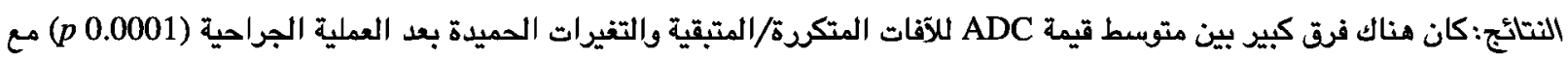

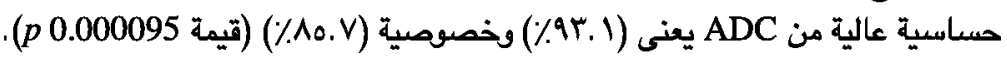

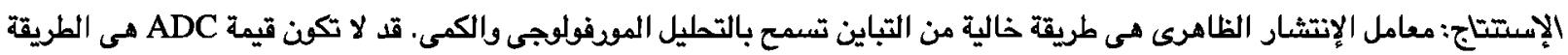

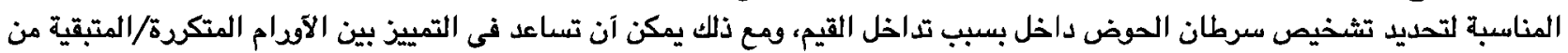
التغيرات اللاحقة للعمليات الجراحية وكذلك كونها مؤشراً جيداً للخلايا السرطانية التى تستجيب العلاج الكئي الكيميائى. 